\title{
Optional Management of Achalasia in 2021: Dilatation or Myotomy
}

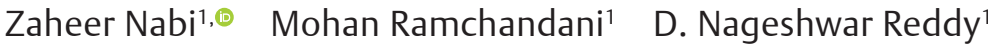 \\ ${ }^{1}$ Asian Institute of Gastroenterology, Hyderabad, Telangana, India \\ Address for correspondence Zaheer Nabi, MD, DNB, Consultant
Gastroenterologist, 6-3-661, Asian Institute of Gastroenterology,
Hyderabad, Telangana 500082, India
(e-mail: zaheernabi1978@gmail.com).
}

\begin{abstract}
Keywords

- esophagus

- achalasia

- endoscopy

- treatment

- Heller's myotomy

- per-oral endoscopic myotomy

Achalasia cardia is a primary motility disorder of the esophagus, defined by lack of normal esophageal peristalsis along with inadequate relaxation of lower esophageal sphincter. The mainstay of management in achalasia includes pneumatic dilatation, Heller's myotomy and peroral endoscopic myotomy (POEM). Pneumatic dilatation and Heller's myotomy have gained maturity over several decades. The current best practice with regard to pneumatic dilatation is graded and on-demand dilatation in appropriately selected cases with type I and II achalasia. Laparoscopic Heller's myotomy plus partial fundoplication is minimally invasive with reduced postoperative reflux and has virtually replaced open Heller's myotomy with or without fundoplication. The subtyping of achalasia using high-resolution manometry bears prognostic significance and may help in choosing appropriate therapeutic modality in these patients. Since all the three modalities are effective for type I and II achalasia, the choice among these depends on the availability, expertise, and patient's preferences. On the other hand, POEM is more effective than pneumatic dilatation and Heller's myotomy and, therefore, preferred in type III achalasia. Although POEM is effective across the spectrum of esophageal motility disorders, the incidence of gastroesophageal reflux is high and needs to be considered while choosing among various options in these patients. In cases with failed POEM, redo POEM appears to be effective in alleviating symptoms.
\end{abstract}

\section{Introduction}

Achalasia cardia, although rare, is the most common primary motility disorder of the esophagus. It is characterized by the lack of normal esophageal peristalsis and deficient relaxation of lower esophageal sphincter (LES). The rising incidence of achalasia indicates better awareness as well as increased utilization of improved diagnostic modalities, especially high-resolution manometry (HRM), which is more sensitive in detecting esophageal motility disorders. ${ }^{1,2}$
The pathophysiology of achalasia is complex and incompletely understood. Irrespective of the underlying triggering factors, the end result is the progressive, immune-mediated destruction of myenteric plexus neurons. ${ }^{3}$ Since none of the currently available treatment modalities halt the degeneration of neurons, it may not be unreasonable to accept that achalasia cardia cannot be cured, although the palliation of symptoms can be achieved in the vast majority of the affected patients. The dominant modalities for the treatment published online April 1, 2021
DOI https://doi.org/ 10.1055/s-0041-1731626 ISSN 0976-5042
(C) 2021. Society of Gastrointestinal Endoscopy of India.

This is an open access article published by Thieme under the terms of the Creative Commons Attribution-NonDerivative-NonCommercial-License, permitting copying and reproduction so long as the original work is given appropriate credit. Contents may not be used for commercial purposes, or adapted, remixed, transformed or built upon. (https://creativecommons.org/licenses/by-nc-nd/4.0/).

Thieme Medical and Scientific Publishers Pvt. Ltd. A-12, 2nd Floor, Sector 2, Noida-201301 UP, India 
of achalasia include pneumatic dilatation (PD), peroral endoscopic myotomy (POEM), and laparoscopic Heller's myotomy (LHM).

In the following sections, we discuss the role of various modalities for the management of achalasia in the current era.

\section{Classification of Esophageal Motility Disorders}

Esophageal motility disorders are broadly divided into disorders of gastroesophageal junction (GEJ) outflow obstruction and disorders of peristalsis. ${ }^{4}$ Disorders of GEJ outflow obstruction include achalasia cardia and esophagogastric junction outflow obstruction (EGJOO), whereas peristaltic disorders without impairment of GEJ outflow are constituted by hypercontractile esophagus and distal esophageal spasm. This subdivision of esophageal motility disorders bears prognostic and therapeutic relevance. Therapeutic modalities like dilatation are mainly directed at GEJ and, therefore, relatively ineffective in spastic esophageal motility disorders, where spasms involving variable length of esophagus are involved in the genesis of symptoms. On the other hand, myotomy (especially endoscopic) can address the spastic segments of esophagus and is preferred in this subgroup. Therefore, the classification of esophageal motility disorders using HRM is crucial before choosing the modality of treatment in these patients.

Endoluminal functional lumen imaging probe (EndoFLIP) is emerging as a useful modality in establishing a diagnosis in cases with equivocal findings on high-resolution esophageal manometry., ${ }^{5,6}$ These cases include those with clinical and radiological findings compatible with achalasia but normal-appearing relaxation on manometry (integrated relaxation pressure $<15 \mathrm{~mm} \mathrm{Hg}$ ) and those with a manometric diagnosis of EGJOO.

\section{Endoscopic Management Options}

The endoscopic management of achalasia include botulinum toxin injection, PD, and POEM. Of these, botulinum toxin injection is reserved for elderly and frail patients, unsuitable for other durable treatment modalities like PD or myotomy. ${ }^{7}$

\section{Pneumatic Dilatation}

PD has been the mainstay of endoscopic management for several decades now. With the availability of low-compliance pneumatic balloons and the graded protocol for dilatation, the outcomes of PD have improved substantially ( - Fig. $\mathbf{1}$ ). Although the technique of PD with regard to the inflation pressure and duration of inflation has not been standardized, it does not seem to influence the results of dilatation. ${ }^{8}$ Nevertheless, accurate positioning of the balloon and disappearance of the waist are important during dilatation for optimal outcomes.

More recently, a hydraulic balloon dilation device (EsoFLIP Crospon Ltd) has been utilized in cases with idiopathic achalasia. ${ }^{9.10}$ Using this system, dilation is achieved by injecting saline, assisted by electrohydraulic pump. This allows stepwise and controlled dilation. Since the catheter is connected to the EndoFLIP system, the diameter as well as cross-sectional area can be measured during dilatation. Although the results from initial studies appear encouraging, comparative studies are required with pneumatic dilatation before recommending hydraulic dilatation in routine practice.

\section{Outcomes}

The outcomes of PD are largely dependent on the protocol used, that is, single versus graded versus graded and on-demand dilatation (-Fig. 1). There is ample data to suggest that single dilatation does not provide durable response and majority ( 70\%) will require retreatment at 5 to 6 years follow-up. ${ }^{11}$ The current best practice is graded dilatation using larger balloons $(30 \mathrm{~mm}, 35 \mathrm{~mm}$, and $40 \mathrm{~mm}$ balloons). The most robust evidence regarding the efficacy of graded and on-demand dilatation was provided by the landmark European achalasia trial. ${ }^{12}$ In this randomized trial, graded dilatation was performed initially using $30 \mathrm{~mm}$ and $35 \mathrm{~mm}$ balloons in all the patients, followed by $40 \mathrm{~mm}$ in symptomatic patients. Subsequently, on-demand dilatation using 35 - and $40-\mathrm{mm}$ balloons was allowed in those with recurrence of symptoms. With this protocol, clinical success was achieved in $90 \%$ and $86 \%$ at 1 and 2-years follow-up, respectively. ${ }^{12}$ Although effective, nearly one-third of patients will experience symptom recurrence after initial series of graded dilatation during follow-up. In these cases, long-term remission can be achieved in approximately 70 to $90 \%$ of cases with repeated and on-demand dilatations. ${ }^{13-16}$

\section{Predictors of Outcomes}

The preprocedure predictors for poor response to PD include young age ( $\leq 40$ years), male gender, high-baseline LES pressure (> $50 \mathrm{~mm} \mathrm{Hg}$ ), dilated esophagus $(>3 \mathrm{~cm})$ and type III achalasia. ${ }^{17,18}$ Postdilatation predictive factors for relapse after PD include incomplete barium emptying $(<50 \%)$ and postdilatation LES pressure $>10 \mathrm{~mm} \mathrm{Hg}$ or $<50 \%$ reduction in the LES pressure. ${ }^{18}$ Of these, young age ( $<40$ years) and

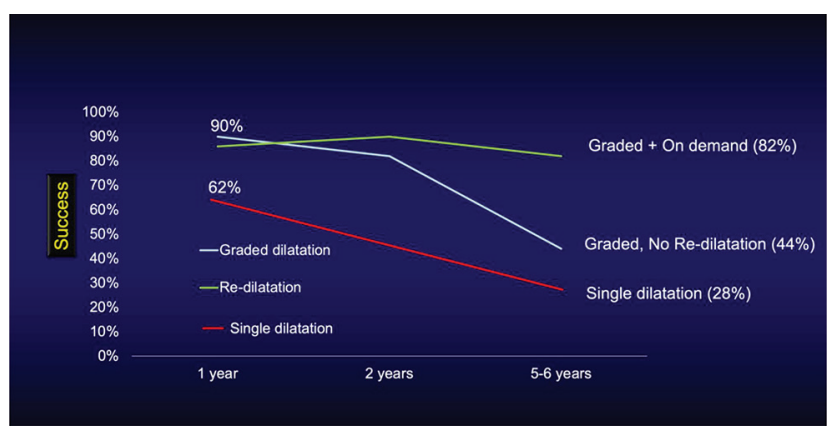

Fig. 1 Outcome of pneumatic dilatation according to the protocol (single vs graded vs graded plus on-demand dilatation). ${ }^{11,12,14}$ 
type III achalasia have been shown to consistently affect the response to PD. ${ }^{19,20}$ Besides these, EndoFLIP is emerging as a novel tool in predicting the immediate outcomes of PD. An increase in EGJ-distensibility index of $1.8 \mathrm{~mm}^{2} / \mathrm{mm} \mathrm{Hg}$ after a single PD predicts an immediate response with an accuracy of $87 \%{ }^{21}$

\section{Adverse Events}

Perforation (1-3\%) is the most dreaded complication of PD. Conservative management is suffice in a substantial proportion of cases, suggesting that the requirement for surgery is not universal. ${ }^{22,23}$ The most important risk factor for perforation is initial dilatation with a $35-\mathrm{mm}$ balloon. ${ }^{8}$ In a systematic review (including 10 studies, 643 patients), the rate of perforations was higher when $35-\mathrm{mm}$ balloon was used for initial dilatations ( $9.3 \%$ vs. $0.97 \%, p=0.0017) .{ }^{8}$ In addition, the risk may be higher in elderly cases (> 65 years). ${ }^{22}$ Therefore, initial dilatations should be performed using a $30-\mathrm{mm}$ balloon, especially in elderly patients. The guidelines by European Society of Gastroenterology (ESGE) recommend dilatation with a $30-\mathrm{mm}$, followed by a $35-\mathrm{mm}$ balloon at a planned interval of 2 to 4 weeks, with a subsequent $40-\mathrm{mm}$ dilation when there is insufficient relief. ${ }^{7}$

\section{Myotomy: Heller's and Endoscopic}

\section{Laparoscopic Heller's Myotomy}

Heller's myotomy was introduced by Sir Ernst Heller in 1914. Initially, Heller's myotomy was performed via laparotomy and not accompanied by a fundoplication wrap. Over a century old, the procedure of Heller's myotomy has undergone several modifications. As of now, the procedure is performed laparoscopically and combined with anterior (Dor) or posterior (Toupet) fundoplication. In the current form, Heller's myotomy is not only less invasive but also associated with less postoperative reflux. ${ }^{24}$

\section{Outcomes}

The safety and efficacy of Heller's myotomy has been established in multiple studies. The short- to midterm clinical success with Heller's myotomy ranges from 80 to $90 \%$ at a follow-up of $\leq 5$ years, whereas symptom remission beyond 10 to 15 years is seen in 70 to $80 \%$ of patients. ${ }^{25-27}$ The notable reasons of failure or symptom relapse after Heller's myotomy include incomplete myotomy, reflux, fibrosis, fundoplication failure, and progression of the disease. Majority of the failures occur within 12 months of surgery, presumably due to incomplete myotomy. ${ }^{28}$ The management options in these cases include relaparoscopic myotomy, PD, and POEM with success rates of 64 to $79 \%, 57$ to $89 \%$, and 80 to $95 \%$, respectively. ${ }^{29}$ However, complications may be higher in re-Heller's myotomy than in primary surgery of achalasia, with a conversion rate to open surgery of $6 \% .^{29}$

\section{Predictors of Outcomes}

The predictors for early dysphagia after Heller's myotomy include preoperative dilatation, fundoplication, and botulinum toxin injection. ${ }^{30}$ Other reported predictors for negative outcomes after surgical myotomy include presence of chest pain, severe preoperative dysphagia, sigmoid esophagus, baseline LES pressure $<30 \mathrm{~mm} \mathrm{Hg}$, and type III achalasia. ${ }^{20,28,31-33}$ The predictors for good response include manometric type II achalasia, high-baseline LES pressure (> $30 \mathrm{~mm} \mathrm{Hg}$ ), and extended myotomy toward gastric side $(3 \mathrm{~cm}){ }^{28,32,34}$

\section{Adverse Events}

The most important intraoperative complication of Heller's myotomy is esophageal or gastric perforation with a cumulative incidence of approximately $7 \% .^{35}$ Majority of the perforations are recognized and repaired intraoperatively with minimal postoperative consequences. GERD is the most frequent delayed adverse event and occurs in about one-third of patients after LHM without fundoplication..$^{35}$ With the addition of partial fundoplication procedure (Dor or Toupet), GERD is noticed in 8 to $10 \%$ of patients during short-term follow-up. ${ }^{24,35}$ However, there is some evidence that the incidence of GERD increases with increasing follow-up, highlighting the need for regular objective assessment in these patients..$^{25,26}$

\section{Peroral Endoscopic Myotomy}

POEM is the most recent addition to the treatment modalities for achalasia cardia. The seminal works by Sumiyama and Pasricha in animal models are credited for the introduction of POEM and other procedures, listed under the umbrella of third space endoscopy. ${ }^{36,37}$

\section{Outcomes}

Since its introduction nearly a decade ago, multiple studies have established the safety and efficacy of POEM in achalasia. In major studies, the efficacy of POEM is $>90 \%$ at 1 to 2 years follow-up..$^{38-40}$ Emerging data suggests that the response to POEM may be durable at midterm follow-up. Clinical success at $\geq 4$ years follow-up has been recorded in 80 to $95 \%$ patients. ${ }^{41-46}$ POEM has also shown to be effective in cases with symptom relapse after PD and Heller's myotomy ${ }^{47}$ The response rate ranges from 80 to $95 \%$ in cases with prior Heller's myotomy at a follow-up ranging from 8.5 to 28 months. ${ }^{48-50}$ In a recent systematic review (9 studies, 272 patients), the pooled clinical success after POEM was 90\% (95\% CI 83.1-96.8\%). ${ }^{51}$ Considering its excellent safety and efficacy, recent guidelines published by prominent gastrointestinal (GI) societies have included POEM in the management protocol for achalasia. ${ }^{52-55}$

The management in cases with relapse of symptoms after POEM has not been studied well. Limited data suggests that re-POEM may provide the best outcomes in these cases. ${ }^{56-58} \mathrm{~A}$ recent multicenter study evaluated the response to various treatments in 99 patients who experienced recurrence of symptoms after POEM..$^{58}$ Clinical success was highest in cases who underwent re-POEM (76\%), followed by PD (60\%) and Heller's myotomy (29\%). In contrast, the response to PD was particularly poor (0-20\%) as compared with POEM (63\%) and Heller's myotomy (45\%) in this setting in another study. ${ }^{57}$ 


\section{Predictors of Outcomes}

There is paucity of studies evaluating the risk factors for poor response after POEM. The available data suggests that the probability of clinical failure is higher in those with pretreatment Eckardt score $\geq 9$, previous treatment, intraprocedural mucosal injury, reflux, and esophageal dilatation ( $\geq$ grade II or $\geq 3.5 \mathrm{~cm}$ ). ${ }^{59-61}$ The Eckardt score is a symptom-based score and comprises four distinct symptoms including dysphagia $(0-3)$, regurgitation (0-3), chest pain (0-3) and weight loss $(0-3)$, whereas esophageal dilatation is graded as grade I $(<3.5 \mathrm{~cm})$, grade II $(\geq 3.5-6 \mathrm{~cm})$ and grade $\mathrm{III}(>6 \mathrm{~cm}) .{ }^{60}$ In two recent studies, risk-scoring systems were devised using these risk factors to predict clinical failure after POEM. ${ }^{60,61}$ These scoring systems need to be validated in future studies to confirm their utility in routine clinical practice.

EndoFLIP is a novel tool that uses impedance planimetry to assess the dynamics of GEJ, including diameter, volume and pressure changes. ${ }^{62}$ The information provided by EndoFLIP can be used to aid in the diagnosis of achalasia as well as to determine the adequacy of myotomy and predict outcomes after treatment. Intraoperative FLIP during POEM has been shown to correlate with treatment outcomes as well as postoperative reflux. In this regard, intraoperative EGJ-cross-sectional area and distensibility index appear to be useful parameters in assessing the response to POEM. ${ }^{62-65}$

\section{Adverse Events}

Major adverse events are uncommon with POEM and occur in 1 to $3 \%$ patients. ${ }^{66}$ Insufflation-related events like subcutaneous emphysema and pneumoperitoneum are common but rarely clinically significant. Mucosal injuries and delayed mucosal barrier failure are the most important clinically relevant group of adverse events. Consequently, oral contrast studies are commonly performed before initiating oral feeds after POEM, although their utility remains questionable in this setting. ${ }^{67}$

Gastroesophageal reflux disease (GERD) is the most common delayed adverse event after POEM. Nearly half of the patients have evidence of GERD on 24-hour pH study, and reflux esophagitis is noticed in 20 to $40 \%$ of patients at 3 to 12 months after POEM. ${ }^{68-70}$ However, majority of the patients are asymptomatic for GERD, develop mild esophagitis (Los Angeles grade A or B) and respond well to proton-pump inhibitor (PPI) therapy. ${ }^{70}$ There are no predictive factors consistently shown to influence the rate of GERD after POEM. Low-integrated relaxation pressure after POEM, female gender, division of oblique fibers during posterior myotomy, excess myotomy along gastric side $(>2-2.5 \mathrm{~cm})$, presence of hiatus hernia, and full thickness myotomy have been shown to be associated with an increased incidence of GERD after POEM in few studies. ${ }^{69,71-73}$ It is important to note that the literature is heterogenous with regard to the predisposing factors for GERD after POEM. Therefore, quality studies are required to confirm and validate the conclusions drawn by these studies.

Several modifications in the technique of POEM have been proposed to reduce the incidence of GERD after POEM. These include preservation of oblique fibers during posterior POEM, addition of fundoplication during anterior POEM, and avoiding excess gastric myotomy $(>3 \mathrm{~cm}) \cdot{ }^{69,72-74}$ However, in the absence of quality data, it may be premature to conclude the efficacy of these strategies.

\section{Pneumatic Dilatation versus Myotomy (POEM and Heller's)}

Graded PD, Heller's myotomy and, more recently, POEM constitute the mainstay of management in achalasia cardia. PD and Heller's myotomy have been compared in multiple quality randomized trials ( $\mathbf{- T a b l e} \mathbf{1}$ ). Overall, the results suggest

Table 1 Outcomes of pneumatic dilatation versus myotomy (endoscopic or surgical) in achalasia cardia

\begin{tabular}{|c|c|c|c|c|c|c|}
\hline Study & $\begin{array}{l}\text { Type of } \\
\text { study }\end{array}$ & $N$ & $\begin{array}{l}\text { Clinical } \\
\text { success }\end{array}$ & $\begin{array}{l}\text { Adverse } \\
\text { events }\end{array}$ & $\begin{array}{l}\text { Follow-up } \\
\text { (years) }\end{array}$ & Reflux esophagitis \\
\hline Boeckxstaens et al $^{12}$ & RCT & $\begin{array}{l}\text { PD } 95 \\
\text { LHM } 106\end{array}$ & $\begin{array}{l}86 \% \\
90 \%\end{array}$ & $\begin{array}{l}4 \% \\
12 \%\end{array}$ & 2 & $\begin{array}{l}19 \% \\
21 \%\end{array}$ \\
\hline Moonen et al ${ }^{14}$ & RCT & $\begin{array}{l}\text { PD } 96 \\
\text { LHM } 105\end{array}$ & $\begin{array}{l}82 \% \\
84 \% \\
\end{array}$ & $\begin{array}{l}5 \% \\
11 \% \\
\end{array}$ & $\geq 5$ & $\begin{array}{l}14 \% \\
18 \% \\
\end{array}$ \\
\hline Meng et $\mathrm{al}^{76}$ & $R$ & $\begin{array}{l}\text { PD } 40 \\
\text { POEM } 32\end{array}$ & $\begin{array}{l}60 \% \\
93 \%\end{array}$ & No major $\mathrm{AE}$ & 3 & NR \\
\hline Zheng et $\mathrm{al}^{78}$ & $R$ & $\begin{array}{l}\text { PD } 26 \\
\text { POEM } 40\end{array}$ & $\begin{array}{l}57.5 \% \\
92.3 \%\end{array}$ & No major AE & 1 & NR \\
\hline Ponds et al $^{79}$ & $\mathrm{RCT}$ & $\begin{array}{l}\text { PD } 66 \\
\text { POEM } 64\end{array}$ & $\begin{array}{l}54 \% \\
92 \%\end{array}$ & $\begin{array}{l}3 \% \\
0 \%\end{array}$ & 2 & $\begin{array}{l}7 \% \\
41 \%\end{array}$ \\
\hline Kim et $\mathrm{al}^{77}$ & $\mathrm{R}$ & $\begin{array}{l}\text { PD } 177 \\
\text { PD } 66\end{array}$ & $\begin{array}{l}68 \% \\
91.8 \%\end{array}$ & $\begin{array}{l}1.7 \% \\
3.1 \%\end{array}$ & 2 & $\begin{array}{l}0.6 \% \\
6.3 \%\end{array}$ \\
\hline Harvey et $\mathrm{al}^{75}$ & $\mathrm{R}$ & $\begin{array}{l}\text { PD } 4748 \\
\text { HM } 2190\end{array}$ & $\begin{array}{l}86.2 \% \\
81.9 \%\end{array}$ & $\begin{array}{l}3.8 \%^{\mathrm{a}} \\
2.6 \%^{\mathrm{a}}\end{array}$ & 10 & NR \\
\hline
\end{tabular}

Abbreviations: LHM, laparoscopic Heller's myotomy; NR, not reported; P, prospective; PD, pneumatic dilatation; POEM, per-oral endoscopic myotomy; $R$, retrospective; $R C T$, randomized controlled trial.

a 30 -day emergency readmission 
Table 2 Outcomes of endoscopic versus surgical myotomy in achalasia cardia

\begin{tabular}{|c|c|c|c|c|c|c|}
\hline Study & $\begin{array}{l}\text { Type of } \\
\text { study }\end{array}$ & $N$ & Clinical success & Adverse events & Follow-up & Reflux esophagitis \\
\hline Bhayani et al ${ }^{81}$ & $P$ & $\begin{array}{l}\text { HM } 64 \\
\text { POEM } 37\end{array}$ & $\begin{array}{l}\text { Dysphagia to solids } \\
29 \% \text { vs } 0 \%\end{array}$ & $\begin{array}{l}17.1 \% \\
10.8 \% \\
\text { (mucosal injuries) }\end{array}$ & $6 \mathrm{~m}$ & NR \\
\hline Kumagai $^{82}$ & $\mathrm{P}$ & $\begin{array}{l}\text { HM } 41 \\
\text { POEM } 42\end{array}$ & $\begin{array}{l}\text { NR } \\
90 \%\end{array}$ & $\begin{array}{l}4.9 \% \\
2.4 \%\end{array}$ & $12 \mathrm{~m}$ & NR \\
\hline Kumbhari et al ${ }^{90}$ & $R$ & $\begin{array}{l}\text { LHM } 26 \\
\text { POEM } 49\end{array}$ & $\begin{array}{l}80.8 \% \\
98 \%\end{array}$ & $\begin{array}{l}27 \% \\
6 \%\end{array}$ & $\begin{array}{l}8.6 \mathrm{~m} \\
21.5 \mathrm{~m}\end{array}$ & NR \\
\hline Chan et al $^{83}$ & $R$ & $\begin{array}{l}\text { LHM } 23 \\
\text { POEM } 33\end{array}$ & $\begin{array}{l}13 \%^{\mathrm{a}}(1 \%) \\
0 \%\end{array}$ & NR & $\begin{array}{l}60 m \\
6 m\end{array}$ & NR \\
\hline Schneider et al ${ }^{84}$ & $R$ & $\begin{array}{l}\text { LHM } 25 \\
\text { POEM } 25\end{array}$ & $\begin{array}{l}84 \% \\
91 \%\end{array}$ & $\begin{array}{l}3^{b} \\
7^{b}\end{array}$ & $\begin{array}{l}158 \text { weeks } \\
36 \text { weeks }\end{array}$ & $\begin{array}{l}31.6 \% \\
53.4 \%\end{array}$ \\
\hline Hanna et al ${ }^{86}$ & $\mathrm{R}$ & $\begin{array}{l}\text { LHM } 54 \\
\text { POEM } 42\end{array}$ & $\begin{array}{l}59 \% \\
74 \%\end{array}$ & $\begin{array}{l}\text { No major } A E \text { in } \\
\text { both groups }\end{array}$ & $\begin{array}{l}37 \mathrm{~m} \\
22 \mathrm{~m}\end{array}$ & $\begin{array}{l}15 \% \\
22 \% \\
\end{array}$ \\
\hline Shea et al ${ }^{87}$ & $\mathrm{P}$ & $\begin{array}{l}\text { HM } 97 \\
\text { POEM } 44\end{array}$ & $\begin{array}{l}65 \% \\
73.3 \%\end{array}$ & NR & $\begin{array}{l}45 \mathrm{~m} \\
18.2 \mathrm{~m}\end{array}$ & NR \\
\hline Wirsching et al $^{88}$ & $P$ & $\begin{array}{l}\text { LHM } 28 \\
\text { POEM } 23\end{array}$ & $\begin{array}{l}13.6 \%^{a} \\
11.1 \%^{\text {a }}\end{array}$ & $\begin{array}{l}14.2 \% \\
8.8 \%\end{array}$ & $\begin{array}{l}102 d \\
83 d\end{array}$ & NR \\
\hline Werner et al $^{80}$ & RCT & $\begin{array}{l}\text { LHM } 109 \\
\text { POEM } 112\end{array}$ & $\begin{array}{l}81.7 \% \\
83 \%\end{array}$ & $\begin{array}{l}7.3 \% \\
2.7 \%\end{array}$ & $24 \mathrm{~m}$ & $\begin{array}{l}29 \% \\
44 \%\end{array}$ \\
\hline Constantini et al ${ }^{101}$ & $R$ & $\begin{array}{l}\text { LHM } \\
\text { POEM }\end{array}$ & $\begin{array}{l}97.7 \% \\
99.3 \%\end{array}$ & $\begin{array}{l}2.1 \% \\
5 \%\end{array}$ & $\begin{array}{l}31 \mathrm{~m} \\
24 \mathrm{~m}\end{array}$ & $\begin{array}{l}15.2 \% \\
37.4 \%\end{array}$ \\
\hline Podboy et al ${ }^{89}$ & $\mathrm{R}$ & $\begin{array}{l}\text { LHM } 43 \\
\text { POEM } 55\end{array}$ & $\begin{array}{l}65.1 \% \\
72.7 \%\end{array}$ & $\begin{array}{l}20.9 \% \\
12.7 \%\end{array}$ & $\begin{array}{l}5.4 \text { years } \\
3.9 \text { years }\end{array}$ & $\begin{array}{l}4.7 \% \\
1.8 \%\end{array}$ \\
\hline
\end{tabular}

Abbreviations: LHM, laparoscopic Heller's myotomy; NR, not reported; P, prospective; POEM, peroral endoscopic myotomy; R, retrospective; RCT, randomized controlled trial.

a Recurrent dysphagia.

${ }^{\mathrm{b}}$ Mucosal injuries (actual numbers).

Table 3 Comparison of the currently available endoscopic modalities for achalasia cardia

\begin{tabular}{|c|c|c|c|}
\hline & $\begin{array}{l}\text { Pneumatic dilatation } \\
\text { (multiple sessions) }\end{array}$ & Peroral endoscopic myotomy & Heller's myotomy \\
\hline Efficacy: short term & $\begin{array}{l}90 \% \text { ( } 1 \text {-year) } \\
54-86 \% \text { ( } 2 \text { years) }\end{array}$ & $>90 \%(1-3$ years $)$ & $\begin{array}{l}93 \%(1 \text {-year }) \\
90 \% \text { ( } 2 \text {-year) }\end{array}$ \\
\hline Efficacy: long-term & 78-93\% ( $\geq 4-5 y e a r s)$ & $80-95 \%$ ( $\geq 4$ years) & $\begin{array}{l}84 \% \text { ( } 5 \text { years }) \\
70-80 \% \text { ( } \geq 10 \text { years })\end{array}$ \\
\hline $\begin{array}{l}\text { Predictors of poor } \\
\text { outcomes }\end{array}$ & $\begin{array}{l}\text { Young age ( } \leq 40 \text { years), type III } \\
\text { achalasia, high LES pressure }>50 \\
\mathrm{~mm} \mathrm{Hg}\end{array}$ & $\begin{array}{l}\text { Prior treatment, mucosal injury, } \\
\text { reflux, sigmoid esophagus, dilated } \\
\text { esophagus }(\geq 3.5 \mathrm{~cm}) \text {, high base- } \\
\text { line Eckardt score }\end{array}$ & $\begin{array}{l}\text { Presence of chest pain, severe preop- } \\
\text { erative dysphagia, sigmoid esopha- } \\
\text { gus, resting LES pressure }<30 \mathrm{~mm} \mathrm{Hg} \text {, } \\
\text { type III achalasia }\end{array}$ \\
\hline Complications & $\begin{array}{l}\text { Perforation (1-3\%), bleeding } \\
(2 \%) \text {, GERD (9\%) }\end{array}$ & $\begin{array}{l}\text { Mucosal injuries }(2-4 \%) \text {, delayed } \\
\text { bleeding }(<1 \%)\end{array}$ & Perforation (7\%) \\
\hline Indications & $\begin{array}{l}\text { Type I and II achalasia preferably } \\
\text { > } 40 \text { years, relapse after POEM } \\
\text { or Heller's myotomy }\end{array}$ & $\begin{array}{l}\text { All subtypes of achalasia espe- } \\
\text { cially type III achalasia, } \\
\text { relapse of symptoms after PD or } \\
\text { Heller's myotomy }\end{array}$ & $\begin{array}{l}\text { All subtypes of achalasia, relapse after } \\
\text { PD or POEM }\end{array}$ \\
\hline Advantages & $\begin{array}{l}\text { Effective in type I and II acha- } \\
\text { lasia, widely available, cost } \\
\text { effective }\end{array}$ & $\begin{array}{l}\text { Durable response, } \\
\text { effective in all subtypes of } \\
\text { achalasia, } \\
\text { more effective than PD and HM in } \\
\text { type III achalasia }\end{array}$ & $\begin{array}{l}\text { Durable response, } \\
\text { effective in all subtypes of achalasia, } \\
\text { less postoperative GERD compared } \\
\text { with POEM }\end{array}$ \\
\hline Disadvantages & $\begin{array}{l}\text { Multiple interventions required, } \\
\text { relatively ineffective in young ( } \leq \\
40 \text { years) and those with type III } \\
\text { achalasia }\end{array}$ & $\begin{array}{l}\text { High incidence of GERD, need of } \\
\text { expertise }\end{array}$ & $\begin{array}{l}\text { Probably inferior to POEM in type } \\
\text { III achalasia, GERD increases with } \\
\text { follow-up }\end{array}$ \\
\hline
\end{tabular}

Abbreviations: GERD, gastroesophageal reflux disease; HM, Heller's myotomy; LES, lower esophageal sphincter; PD, pneumatic dilatation. 
that these two modalities are comparable with respect to short- and long-term outcomes. ${ }^{12,14}$ On the other hand, a single series of dilatation may not provide durable response and, therefore, regarded as inferior to Heller's myotomy. The protocol of dilatation utilized in the landmark European achalasia trial, that is,, graded and on-demand, has been widely accepted as the standard of care in cases undergoing PD. With this protocol, the clinical success at 2 years (86 vs. 90\%) and $\geq 5$ years ( $84 \%$ vs. $82 \%$ ) were comparable in PD and Heller's myotomy groups, respectively. ${ }^{12}$ The results of this study were further substantiated by a large nationwide cohort study, including 6938 subjects, where PD and Heller's myotomy had similar efficacy over 10 -years follow-up (86\% vs. $82 \%$ ). ${ }^{75}$

POEM has been compared with PD in several cohort studies majority of which conclude that POEM is superior to PD (- Table 1)..$^{76-78}$ However, the important shortcomings of these trials include retrospective design, suboptimal protocol of PD, and difference in the duration of follow-up. More recently, two high quality randomized trials compared POEM to PD and Heller's myotomy. ${ }^{79,80}$ In the multicenter randomized trial by Ponds et al, clinical success with POEM was superior to PD at 2-years follow-up (92\% vs. 54\%, $p<$ $0.001) .{ }^{79}$ However, GERD (reflux esophagitis) was more in the POEM group (41\% vs. 7\%; $p=0.002$ ).

Endoscopic and surgical myotomy appear comparable with regard to efficacy at least in short-term follow-up (-Table 2). ${ }^{80-89}$ In the randomized study by Werner and colleagues, POEM was noninferior to laparoscopic Heller's myotomy with Dor's fundoplication at 2 years (83\% vs. $81.7 \%$ ). However, the downside of POEM was a higher incidence of reflux esophagitis ( $44 \%$ vs. $29 \%$ ). ${ }^{80}$

POEM may be superior to Heller's myotomy in cases with type III achalasia and other nonachalasia spastic esophageal motility disorders like hypercontractile esophagus and distal esophageal spasm. ${ }^{89,90}$ In a retrospective cohort study, the clinical success after POEM was significantly better than Heller's myotomy in selected cases with type III achalasia. ${ }^{90}$ Subsequent studies have also confirmed excellent outcomes with POEM in spastic motility disorders of esophagus. ${ }^{91-99}$ The ability to perform long esophageal

Table 4 Guidelines and recommendations for the endoscopic management of achalasia cardia

\begin{tabular}{|c|c|c|c|}
\hline & ESGE $^{53}$ & $\mathrm{ASGE}^{54}$ & $\mathrm{ACG}^{55}$ \\
\hline $\begin{array}{l}\text { Botulinum } \\
\text { toxin inj. }\end{array}$ & $\begin{array}{l}\text { - Safe and effective } \\
\text { - Indicated in patients unfit for more } \\
\text { invasive treatments, or in whom a } \\
\text { more definite treatment needs to } \\
\text { be deferred }^{\text {a }}\end{array}$ & $\begin{array}{l}\text { - Should be avoided as definitive } \\
\text { therapy for achalasia patients } \\
\text { - Should be reserved for patients } \\
\text { who are not candidates for } \\
\text { other definitive therapies }{ }^{\text {a }}\end{array}$ & $\begin{array}{l}\text { - First-line therapy for patients with } \\
\text { achalasia that are unfit for definitive } \\
\text { therapies }^{\text {b }} \\
\text { - BTX injection does not significantly } \\
\text { affect performance and outcomes of } \\
\text { myotomy }\end{array}$ \\
\hline $\begin{array}{l}\text { Pneumatic } \\
\text { dilatation }\end{array}$ & $\begin{array}{l}\text { Graded PD is safe and efficacious } \\
\text { treatment } \\
\text { for achalasia }^{d}\end{array}$ & $\begin{array}{l}\text { - PD is an effective modality for } \\
\text { achalasiad } \\
\text { - PD is preferred over BTX } \\
\text { injection for patients with } \\
\text { achalasiad } \\
\text { - PD and LHM are comparable } \\
\text { for type I and II achalasiaa }\end{array}$ & $\begin{array}{l}\text { - } \mathrm{PD} \text { is superior to medical therapy in } \\
\text { relieving symptoms and physiologic } \\
\text { parameters of esophageal emptying } \\
\text { - } \mathrm{PD} \text { is superior to medical therapy in } \\
\text { relieving symptoms and physiologic } \\
\text { parameters of esophageal emptying }\end{array}$ \\
\hline $\begin{array}{l}\text { Laparoscopic } \\
\text { Heller's } \\
\text { myotomy }\end{array}$ & $\begin{array}{l}\text { - LHM combined with an antireflux } \\
\text { procedure is an effective and rel- } \\
\text { atively safe therapy for achalasiaa } \\
\text { - LHM, graded repetitive pneumatic } \\
\text { dilation, and POEM have compara- } \\
\text { ble efficacy } \\
\text { - Recurrent or persistent dysphagia } \\
\text { after LHM should be managed } \\
\text { with PD, POEM or redo surgery }\end{array}$ & $\begin{array}{l}\text { - LHM, PD and POEM are effec- } \\
\text { tive and comparable thera- } \\
\text { peutic modalities for patients } \\
\text { with type I and II achalasiaa }\end{array}$ & $\begin{array}{l}\text { - Myotomy with fundoplication is supe- } \\
\text { rior to myotomy without fundoplica- } \\
\text { tion in controlling distal esophageal } \\
\text { acid exposure } \\
\text { - Dor or Toupet fundoplication is rec- } \\
\text { ommended to control esophageal acid } \\
\text { exposure }^{\text {exp }}\end{array}$ \\
\hline $\begin{array}{l}\text { Peroral } \\
\text { endoscopic } \\
\text { myotomy }\end{array}$ & $\begin{array}{l}\text { POEM is a safe and efficacious treat- } \\
\text { ment for achalasiad }\end{array}$ & $\begin{array}{l}\text { - POEM is an effective modality } \\
\text { for achalasiad } \\
\text { - POEM should be preferred in } \\
\text { type III achalasiab } \\
\text { - POEM and LHM are compara- } \\
\text { ble for type I and II achalasiac }\end{array}$ & $\begin{array}{l}\text { - Tailored POEM or LHM preferred over } \\
\text { dilatation for type III achalasia } \\
\text { - POEM would be a better treatment } \\
\text { option in those with type III achalasia. } \\
\text { - POEM is associated with a higher inci- } \\
\text { dence of GERD as compared with LHM } \\
\text { with fundoplication and PD } \\
\text { - POEM, PD and LHM are comparable in } \\
\text { type I and II achalasiac }\end{array}$ \\
\hline
\end{tabular}

Abbreviations: BTX, botulinum toxin; LHM, laparoscopic Heller's myotomy; PD, pneumatic dilatation; POEM, peroral endoscopic myotomy.

bery low evidence.

c low evidence.

a moderate evidence.

${ }^{\mathrm{d}}$ high evidence. 


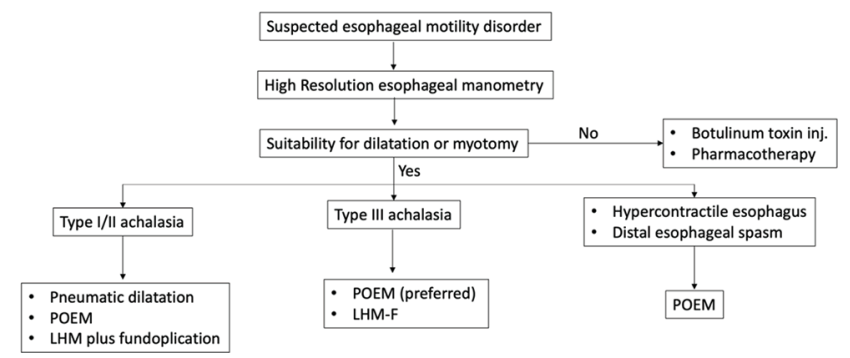

Fig. 2 Approach to esophageal motility disorders in treatment naïve cases.

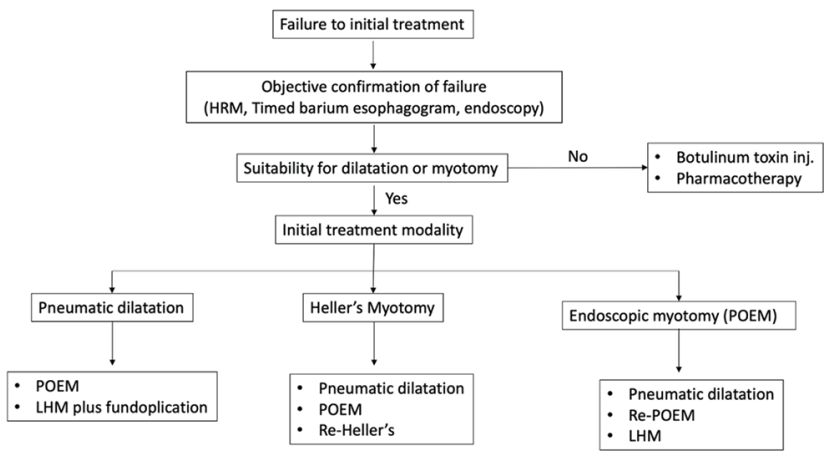

Fig. 3 Approach to esophageal motility disorders in prior treatment failed cases.

myotomies explains the superior response with POEM in these cases. A recent meta-analysis described the clinical outcomes after Heller's myotomy and POEM for achalasia based on manometric subtypes. ${ }^{100}$ POEM was superior to Heller's myotomy for type I (95\% vs. 81\%) and III (93\% vs. 71\%) achalasia. The recent guidelines by the American Society for Gastrointestinal Endoscopy (ASGE) and the American College of Gastroenterology (ACG) recommend POEM for type III achalasia (very low quality evidence). ${ }^{54,55}$ Other reported advantages of POEM over Heller's myotomy include shorter procedure time, less postoperative pain, and shorter hospitalization. ${ }^{81,83,85}$

\section{Individualized Management of Achalasia: Putting it all Together}

Currently, there are three effective modalities available for the management of achalasia, including PD, POEM, and Heller's myotomy ( - Table 3 ). The choice among these modalities is based on several factors which include availability and expertise, presence of risk factors of poor response with a particular modality, and patient's preferences ( - Fig. 2 ). The major gastroenterology societies have published the updated guidelines regarding the management of achalasia and allied disorders. ${ }^{52-55}$ The salient features of these guidelines have been summarized in - Table 4 .

The pros and cons of each procedure should be detailed to the patients for a shared decision-making. PD is widely available, safe, cost-effective and provides durable response in appropriately selected patients. The patients should be aware regarding the requirement of repeated interventions and a small risk of perforation associated with PD. In cases with presumed poor response to PD (age $<40$ years, type III achalasia, high LES pressure $>50 \mathrm{~mm} \mathrm{Hg}$ ), endoscopic or surgical myotomy is preferable. Endoscopic and surgical myotomy are similarly effective across all age groups and subtypes of achalasia, except in cases with type III achalasia, where POEM may be more effective than Heller's myotomy. The important limitations with endoscopic myotomy are lack of data on long-term efficacy, that is, beyond 10 years and high incidence of postoperative GERD. Therefore, the long-term need for antireflux medications should be explained. In cases with relapse of symptoms after myotomy (POEM or Heller's), PD may be a reasonable first-line treatment with acceptable results, especially after failed Heller's myotomy. Alternatively, remyotomy, especially POEM, may be performed with superior outcomes as compared with re-Heller's myotomy, although the data is limited ( - Fig. $\mathbf{3}$ ).

\section{Abbreviations \\ POEM per-oral endoscopic myotomy \\ ACG American College of Gastroenterology \\ ASGE American Society of Gastrointestinal Endoscopy \\ ESGE European Society of Gastrointestinal Endoscopy \\ GEJ gastroesophageal junction \\ GERD gastroesophageal reflux disease \\ HRM high resolution manometry \\ LES lower esophageal sphincter \\ PD pneumatic dilatation \\ Funding}

The authors (Z.N., M.R., D.N.R) received no funding or support for this manuscript.

\section{Conflict of Interest}

All the authors declare no conflict of interest.

\section{Acknowledgments}

None.

\section{References}

1 Roman S, Huot L, Zerbib F, et al. High-resolution manometry improves the diagnosis of esophageal motility disorders in patients with dysphagia: a randomized multicenter study. Am J Gastroenterol 2016;111(3):372-380

2 Samo S, Carlson DA, Gregory DL, Gawel SH, Pandolfino JE, Kahrilas PJ. Incidence and prevalence of achalasia in Central Chicago, 2004-2014, since the widespread use of high-resolution manometry. Clin Gastroenterol Hepatol 2017;15(3):366-373

3 Rieder E, Fernandez-Becker NQ Sarosiek J, Guillaume A, Azagury DE, Clarke JO. Achalasia: physiology and diagnosis. Ann N Y Acad Sci 2020;1482(1):85-94

4 Yadlapati R, Kahrilas PJ, Fox MR, et al. Esophageal motility disorders on high-resolution manometry: Chicago classification version 4.0@. Neurogastroenterol Motil 2021;33(1):e14058

5 Carlson DA, Kahrilas PJ, Lin Z, et al. Evaluation of esophageal motility utilizing the functional lumen imaging probe. Am J Gastroenterol 2016;111(12):1726-1735

6 Ponds FA, Bredenoord AJ, Kessing BF, Smout AJ. Esophagogastric junction distensibility identifies achalasia subgroup with manometrically normal esophagogastric junction relaxation. Neurogastroenterol Motil 2017;29(1):29 
7 Weusten BLAM, Barret M, Bredenoord AJ, et al. Endoscopic management of gastrointestinal motility disorders part 1: European Society of Gastrointestinal Endoscopy (ESGE) Guideline. Endoscopy 2020;52(6):498-515

8 van Hoeij FB, Prins LI, Smout AJPM, Bredenoord AJ. Efficacy and safety of pneumatic dilation in achalasia: A systematic review and meta-analysis. Neurogastroenterol Motil 2019;31(7):e13548

9 Schnurre L, Murray FR, Schindler V, et al. Short-term outcome after singular hydraulic EsoFLIP dilation in patients with achalasia: a feasibility study. Neurogastroenterol Motil 2020;32(9):e13864

10 Kappelle WF, Bogte A, Siersema PD. Hydraulic dilation with a shape-measuring balloon in idiopathic achalasia: a feasibility study. Endoscopy 2015;47(11):1028-1034

11 Vela MF, Richter JE, Khandwala F, et al. The long-term efficacy of pneumatic dilatation and Heller myotomy for the treatment of achalasia. Clin Gastroenterol Hepatol 2006;4(5):580-587

12 Boeckxstaens GE, Annese V, des Varannes SB, et al. European Achalasia Trial Investigators. Pneumatic dilation versus laparoscopic Heller's myotomy for idiopathic achalasia. N Engl J Med 2011;364(19):1807-1816

13 Hulselmans M, Vanuytsel T, Degreef T, et al. Long-term outcome of pneumatic dilation in the treatment of achalasia. Clin Gastroenterol Hepatol 2010;8(1):30-35

14 Moonen A, Annese V, Belmans A, et al. Long-term results of the European achalasia trial: a multicentre randomised controlled trial comparing pneumatic dilation versus laparoscopic Heller myotomy. Gut 2016;65(5):732-739

15 Zerbib F, Thétiot V, Richy F, Benajah DA, Message L, Lamouliatte $\mathrm{H}$. Repeated pneumatic dilations as long-term maintenance therapy for esophageal achalasia. Am J Gastroenterol 2006;101(4):692-697

16 Bravi I, Nicita MT, Duca P, et al. A pneumatic dilation strategy in achalasia: prospective outcome and effects on oesophageal motor function in the long term. Aliment Pharmacol Ther 2010;31(6):658-665

17 Müller M, Keck C, Eckardt AJ, et al. Outcomes of pneumatic dilation in achalasia: Extended follow-up of more than 25 years with a focus on manometric subtypes. J Gastroenterol Hepatol 2018;33(5):1067-1074

18 Felix VN. Results of pneumatic dilation in treating achalasia: predictive factors. Ann N Y Acad Sci 2018;1434(1):124-131

19 Pratap N, Kalapala R, Darisetty S, et al. Achalasia cardia subtyping by high-resolution manometry predicts the therapeutic outcome of pneumatic balloon dilatation. J Neurogastroenterol Motil 2011;17(1):48-53

20 Pandolfino JE, Kwiatek MA, Nealis T, Bulsiewicz W, Post J, Kahrilas PJ. Achalasia: a new clinically relevant classification by high-resolution manometry. Gastroenterology 2008;135(5):1526-1533

21 Wu PI, Szczesniak MM, Craig PI, et al. Novel intra-procedural distensibility measurement accurately predicts immediate outcome of pneumatic dilatation for idiopathic achalasia. Am J Gastroenterol 2018;113(2):205-212

22 Vanuytsel T, Lerut T, Coosemans W, et al. Conservative management of esophageal perforations during pneumatic dilation for idiopathic esophageal achalasia. Clin Gastroenterol Hepatol 2012;10(2):142-149

23 Ghoshal UC, Karyampudi A, Verma A, et al. Perforation following pneumatic dilation of achalasia cardia in a university hospital in northern India: A two-decade experience. Indian J Gastroenterol 2018;37(4):347-352

24 Richards WO, Torquati A, Holzman MD, et al. Heller myotomy versus Heller myotomy with Dor fundoplication for achalasia: a prospective randomized double-blind clinical trial. Ann Surg 2004;240(3):405-412, discussion 412-415
25 Csendes A, Braghetto I, Burdiles P, Korn O, Csendes P, Henríquez A. Very late results of esophagomyotomy for patients with achalasia: clinical, endoscopic, histologic, manometric, and acid reflux studies in 67 patients for a mean follow-up of 190 months. Ann Surg 2006;243(2):196-203

26 Ortiz A, de Haro LF, Parrilla P, et al. Very long-term objective evaluation of heller myotomy plus posterior partial fundoplication in patients with achalasia of the cardia. Ann Surg 2008;247(2):258-264

27 Csendes A, Orellana O, Figueroa M, Lanzarini E, Panza B. Long-term (17 years) subjective and objective evaluation of the durability of laparoscopic Heller esophagomyotomy in patients with achalasia of the esophagus (90\% of follow-up): a real challenge to POEM. Surg Endosc 2021;(e-pub ahead of print). doi:10.1007/s00464-020-08273-1

28 Zaninotto G, Costantini M, Rizzetto C, et al. Four hundred laparoscopic myotomies for esophageal achalasia: a single centre experience. Ann Surg 2008;248(6):986-993

29 Fernandez-Ananin S, Fernández AF, Balagué C, Sacoto D, Targarona EM. What to do when Heller's myotomy fails? Pneumatic dilatation, laparoscopic remyotomy or peroral endoscopic myotomy: A systematic review. J Minim Access Surg 2018;14(3):177-184

30 Finley CJ, Kondra J, Clifton J, Yee J, Finley R. Factors associated with postoperative symptoms after laparoscopic Heller myotomy. Ann Thorac Surg 2010;89(2):392-396

31 Salvador R, Costantini M, Zaninotto $G$, et al. The preoperative manometric pattern predicts the outcome of surgical treatment for esophageal achalasia. J Gastrointest Surg 2010;14(11):1635-1645

32 Torquati A, Richards WO, Holzman MD, Sharp KW. Laparoscopic myotomy for achalasia: predictors of successful outcome after 200 cases. Ann Surg 2006;243(5):587-591, discussion 591-593

33 Khajanchee YS, Kanneganti S, Leatherwood AE, Hansen PD, Swanström LL. Laparoscopic Heller myotomy with Toupet fundoplication: outcomes predictors in 121 consecutive patients. Arch Surg 2005;140(9):827-833, discussion 833-834

34 Oelschlager BK, Chang L, Pellegrini CA. Improved outcome after extended gastric myotomy for achalasia. Arch Surg 2003;138(5):490-495, discussion 495-497

35 Campos GM, Vittinghoff E, Rabl C, et al. Endoscopic and surgical treatments for achalasia: a systematic review and meta-analysis. Ann Surg 2009;249(1):45-57

36 Sumiyama K, Gostout CJ, Rajan E, Bakken TA, Knipschield MA, Marler RJ. Submucosal endoscopy with mucosal flap safety valve. Gastrointest Endosc 2007;65(4):688-694

37 Pasricha PJ, Hawari R, Ahmed I, et al. Submucosal endoscopic esophageal myotomy: a novel experimental approach for the treatment of achalasia. Endoscopy 2007;39(9):761-764

38 Ramchandani M, Nageshwar Reddy D, Darisetty S, et al. Peroral endoscopic myotomy for achalasia cardia: treatment analysis and follow up of over 200 consecutive patients at a single center. Dig Endosc 2016;28(1):19-26

39 Shiwaku $\mathrm{H}$, Inoue $\mathrm{H}$, Onimaru $\mathrm{M}$, et al. Multicenter collaborative retrospective evaluation of peroral endoscopic myotomy for esophageal achalasia: analysis of data from more than 1300 patients at eight facilities in Japan. Surg Endosc 2020;34(1):464-468

40 Shiwaku $\mathrm{H}$, Inoue $\mathrm{H}$, Sato $\mathrm{H}$, et al. Peroral endoscopic myotomy for achalasia: a prospective multicenter study in Japan. Gastrointest Endosc 2020;91(5):1037-1044.e2, e2

41 Guo H, Yang H, Zhang X, et al. Long-term outcomes of peroral endoscopic myotomy for patients with achalasia: a retrospective single-center study. Dis Esophagus 2017;30(5):1-6

$42 \mathrm{Li}$ QL, Wu QN, Zhang XC, et al. Outcomes of per-oral endoscopic myotomy for treatment of esophageal achalasia with a median 
follow-up of 49 months. Gastrointest Endosc 2018;87(6):14051412.e3, e3

43 Teitelbaum EN, Dunst CM, Reavis KM, et al. Clinical outcomes five years after POEM for treatment of primary esophageal motility disorders. Surg Endosc 2018;32(1):421-427

$44 \mathrm{He}$ C, Li M, Lu B, et al. Long-term efficacy of peroral endoscopic myotomy for patients with achalasia: outcomes with a median follow-up of 36 months. Dig Dis Sci 2019;64(3):803-810

45 Brewer Gutierrez OI, Moran RA, Familiari P, et al. Long-term outcomes of per-oral endoscopic myotomy in achalasia patients with a minimum follow-up of 4 years: a multicenter study. Endosc Int Open 2020;8(5):E650-E655

46 McKay SC, Dunst CM, Sharata AM, et al. POEM: clinical outcomes beyond 5 years. Surg Endosc 2021; (e-pub ahead of print). doi:10.1007/s00464-020-08031-3

47 Nabi Z, Ramchandani M, Chavan R, et al. Peroral endoscopic myotomy in treatment-naïve achalasia patients versus prior treatment failure cases. Endoscopy 2018;50(4):358-370

48 Ngamruengphong $\mathrm{S}$, Inoue $\mathrm{H}$, Ujiki $\mathrm{MB}$, et al. Efficacy and safety of peroral endoscopic myotomy for treatment of achalasia after failed Heller myotomy. Clin Gastroenterol Hepatol 2017;15(10):1531-1537.e3, e3

49 Tyberg A, Sharaiha RZ, Familiari P, et al. Peroral endoscopic myotomy as salvation technique post-Heller: International experience. Dig Endosc 2018;30(1):52-56

50 Zhang X, Modayil RJ, Friedel D, et al. Per-oral endoscopic myotomy in patients with or without prior Heller's myotomy: comparing long-term outcomes in a large U.S. single-center cohort (with videos) Gastrointest Endosc 2018;87(4):972-985

51 Huang Z, Cui Y, Li Y, Chen M, Xing X. Peroral endoscopic myotomy for patients with achalasia with previous Heller myotomy: a systematic review and meta-analysis. Gastrointest Endosc 2021;93(1):47-56.e5, e5

52 Jung HK, Hong SJ, Lee OY, et al. Korean Society of Neurogastroenterology and Motility. 2019 Seoul Consensus on Esophageal Achalasia Guidelines. J Neurogastroenterol Motil 2020;26(2):180-203

53 Oude Nijhuis RAB, Zaninotto G, Roman S, et al. European guidelines on achalasia: United European Gastroenterology and European Society of Neurogastroenterology and Motility recommendations. United European Gastroenterol J 2020;8(1):13-33

54 Khashab MA, Vela MF, Thosani $\mathrm{N}$, et al. ASGE guideline on the management of achalasia. Gastrointest Endosc 2020;91(2):213-227.e6, e6

55 Vaezi MF, Pandolfino JE, Yadlapati RH, Greer KB, Kavitt RT. ACG Clinical Guidelines: Diagnosis and Management of Achalasia. Am J Gastroenterol 2020;115(9):1393-1411

56 Tyberg A, Seewald S, Sharaiha RZ, et al. A multicenter international registry of redo per-oral endoscopic myotomy (POEM) after failed POEM. Gastrointest Endosc 2017;85(6):1208-1211

57 van Hoeij FB, Ponds FA, Werner Y, et al. Management of recurrent symptoms after per-oral endoscopic myotomy in achalasia. Gastrointest Endosc 2018;87(1):95-101

58 Ichkhanian Y, Assis D, Familiari P, et al. Management of patients after failed peroral endoscopic myotomy: a multicenter study. Endoscopy 2020;(e-pub ahead of print). doi: /a-1312-049

59 Ren Y, Tang X, Chen Y, et al. Pre-treatment Eckardt score is a simple factor for predicting one-year peroral endoscopic myotomy failure in patients with achalasia. Surg Endosc 2017;31(8):3234-3241

60 Urakami S, Abe H, Tanaka S, et al. Development of a preoperative risk-scoring system for predicting poor responders to peroral endoscopic myotomy. Gastrointest Endosc 2021;93(2):398-405

61 Liu XY, Cheng J, Chen WF, et al. A risk-scoring system to predict clinical failure for patients with achalasia after peroral endoscopic myotomy. Gastrointest Endosc 2020;91(1):33-40.e1, e1
62 Hirano I, Pandolfino JE, Boeckxstaens GE. Functional Lumen Imaging Probe for the Management of Esophageal Disorders: Expert Review From the Clinical Practice Updates Committee of the AGA Institute. Clin Gastroenterol Hepatol 2017;15(3):325-334

63 Donnan EN, Pandolfino JE. Applying the functional luminal imaging probe to esophageal disorders. Curr Gastroenterol Rep 2020;22(3):10

64 Su B, Callahan ZM, Novak S, Kuchta K, Ujiki MB. Using impedance planimetry (EndoFLIP) to evaluate myotomy and predict outcomes after surgery for achalasia. J Gastrointest Surg 2020;24(4):964-971

65 Attaar M, Su B, Wong HJ, et al. Intraoperative impedance planimetry (EndoFLIP) results and development of esophagitis in patients undergoing peroral endoscopic myotomy (POEM) Surg Endosc 2020;(e-pub ahead of print). doi:10.1007/s00464-020-07876-y

66 Nabi Z, Reddy DN, Ramchandani M. Adverse events during and after per-oral endoscopic myotomy: prevention, diagnosis, and management. Gastrointest Endosc 2018;87(1):4-17

67 Reddy CA, Tavakkoli A, Abdul-Hussein M, et al. The clinical impact of routine esophagram after peroral endoscopic myotomy. Gastrointest Endosc 2020;93(1):102-106

68 Kumbhari V, Familiari P, Bjerregaard NC, et al. Gastroesophageal reflux after peroral endoscopic myotomy: a multicenter case-control study. Endoscopy 2017;49(7):634-642

69 Nabi Z, Ramchandani M, Reddy DN. Per-oral endoscopic myotomy and gastroesophageal reflux: Where do we stand after a decade of "POETRY"? Indian J Gastroenterol 2019;38(4):287-294

70 Nabi Z, Ramchandani M, Kotla R, et al. Gastroesophageal reflux disease after peroral endoscopic myotomy is unpredictable, but responsive to proton pump inhibitor therapy: a large, single-center study. Endoscopy 2020;52(8):643-651

71 Ramirez M, Zubieta C, Ciotola F, et al. Per oral endoscopic myotomy vs. laparoscopic Heller myotomy, does gastric extension length matter? Surg Endosc 2018;32(1):282-288

72 Grimes KL, Bechara R, Shimamura Y, et al. Gastric myotomy length affects severity but not rate of post-procedure reflux: 3-year follow-up of a prospective randomized controlled trial of double-scope per-oral endoscopic myotomy (POEM) for esophageal achalasia. Surg Endosc 2020;34(7):2963-2968

73 Tanaka S, Toyonaga T, Kawara F, et al. Novel per-oral endoscopic myotomy method preserving oblique muscle using two penetrating vessels as anatomic landmarks reduces postoperative gastroesophageal reflux. J Gastroenterol Hepatol 2019;34(12):2158-2163

74 Inoue $\mathrm{H}$, Shiwaku H, Kobayashi Y, et al. Statement for gastroesophageal reflux disease after peroral endoscopic myotomy from an international multicenter experience. Esophagus 2020;17(1):3-10

75 Harvey PR, Coupland B, Mytton J, Evison F, Patel P, Trudgill NJ. Outcomes of pneumatic dilatation and Heller's myotomy for achalasia in England between 2005 and 2016. Gut 2019;68(7):1146-1151

76 Meng F, Li P, Wang Y, et al. Peroral endoscopic myotomy compared with pneumatic dilation for newly diagnosed achalasia. Surg Endosc 2017;31(11):4665-4672

77 Kim GH, Jung KW, Jung HY, et al. Superior clinical outcomes of peroral endoscopic myotomy compared with balloon dilation in all achalasia subtypes. J Gastroenterol Hepatol 2019;34(4):659-665

78 Zheng Z, Zhao C, Su S, et al. Peroral endoscopic myotomy versus pneumatic dilation - result from a retrospective study with 1-year follow-up. Z Gastroenterol 2019;57(3):304-311

79 Ponds FA, Fockens P, Lei A, et al. Effect of peroral endoscopic myotomy vs pneumatic dilation on symptom severity and treatment outcomes among treatment-naive 
patients with achalasia: a randomized clinical trial. JAMA 2019;322(2):134-144

80 Werner YB, Hakanson B, Martinek J, et al. Endoscopic or surgical myotomy in patients with idiopathic achalasia. N Engl J Med 2019;381(23):2219-2229

81 Bhayani NH, Kurian AA, Dunst CM, Sharata AM, Rieder E, Swanstrom LL. A comparative study on comprehensive, objective outcomes of laparoscopic Heller myotomy with per-oral endoscopic myotomy (POEM) for achalasia. Ann Surg 2014;259(6):1098-1103

82 Kumagai K, Tsai JA, Thorell A, Lundell L, Håkanson B. Per-oral endoscopic myotomy for achalasia. Are results comparable to laparoscopic Heller myotomy? Scand J Gastroenterol 2015;50(5):505-512

83 Chan SM, Wu JC, Teoh AY, et al. Comparison of early outcomes and quality of life after laparoscopic Heller's cardiomyotomy to peroral endoscopic myotomy for treatment of achalasia. Dig Endosc 2016;28(1):27-32

84 Schneider AM, Louie BE, Warren HF, Farivar AS, Schembre DB, Aye RW. A Matched comparison of per oral endoscopic myotomy to laparoscopic Heller myotomy in the treatment of achalasia. J Gastrointest Surg 2016;20(11):1789-1796

85 Docimo S, Jr, Mathew A, Shope AJ, Winder JS, Haluck RS, Pauli EM. Reduced postoperative pain scores and narcotic use favor per-oral endoscopic myotomy over laparoscopic Heller myotomy. Surg Endosc 2017;31(2):795-800

86 Hanna AN, Datta J, Ginzberg S, Dasher K, Ginsberg GG, Dempsey DT. Laparoscopic Heller myotomy vs per oral endoscopic myotomy: patient-reported outcomes at a single institution. J Am Coll Surg 2018;226(4):465-472.e1, e1

87 Shea GE, Johnson MK, Venkatesh M, et al. Long-term dysphagia resolution following POEM versus Heller myotomy for achalasia patients. Surg Endosc 2020;34(4):1704-1711

88 Wirsching A, Boshier PR, Klevebro F, et al. Comparison of costs and short-term clinical outcomes of per-oral endoscopic myotomy and laparoscopic Heller myotomy. Am J Surg 2019;218(4):706-711

89 Podboy AJ, Hwang JH, Rivas $\mathrm{H}$, et al. Long-term outcomes of per-oral endoscopic myotomy compared to laparoscopic Heller myotomy for achalasia: a single-center experience. Surg Endosc 2021;35(2):792-801

90 Kumbhari V, Tieu AH, Onimaru M, et al. Peroral endoscopic myotomy (POEM) vs laparoscopic Heller myotomy (LHM) for the treatment of Type III achalasia in 75 patients: a multicenter comparative study. Endosc Int Open 2015;3(3):E195-E201

91 Khan MA, Kumbhari V, Ngamruengphong S, et al. Is POEM the answer for management of spastic esophageal disorders? A systematic review and meta-analysis. Dig Dis Sci 2017;62(1):35-44

92 Zhang W, Linghu EQ. Peroral endoscopic myotomy for type III achalasia of Chicago Classification: outcomes with a minimum follow-up of 24 months. J Gastrointest Surg 2017;21(5):785-791

93 Albers D, Frieling T, Dakkak D, et al. Peroral endoscopic myotomy (POEM) is effective in treatment of noncardiac chest pain caused by hypercontractile esophageal motility disorders: results of the POEM-HYPE-Study. Z Gastroenterol 2018;56(11):1337-1342

94 Khashab MA, Familiari P, Draganov PV, et al. Peroral endoscopic myotomy is effective and safe in non-achalasia esophageal motility disorders: an international multicenter study. Endosc Int Open 2018;6(8):E1031-E1036

95 Chandan S, Mohan BP, Chandan OC, et al. Clinical efficacy of per-oral endoscopic myotomy (POEM) for spastic esophageal disorders: a systematic review and meta-analysis. Surg Endosc 2019;34(2):707-718

96 Filicori F, Dunst CM, Sharata A, et al. Long-term outcomes following POEM for non-achalasia motility disorders of the esophagus. Surg Endosc 2019;33(5):1632-1639

97 Kane ED, Budhraja V, Desilets DJ, Romanelli JR. Myotomy length informed by high-resolution esophageal manometry (HREM) results in improved per-oral endoscopic myotomy (POEM) outcomes for type III achalasia. Surg Endosc 2019;33(3):886-894

98 Bernardot L, Roman S, Barret M, et al. Efficacy of per-oral endoscopic myotomy for the treatment of non-achalasia esophageal motor disorders. Surg Endosc 2020;34(12):5508-5515

99 Nabi Z, Chavan R, Ramchandani M, et al. Long-term outcomes of per-oral endoscopic myotomy in spastic esophageal motility disorders: a large, single-center study. J Clin Gastroenterol 2020

100 Andolfi C, Fisichella PM. Meta-analysis of clinical outcome after treatment for achalasia based on manometric subtypes. Br J Surg 2019;106(4):332-341

101 Costantini A, Familiari P, Costantini M, et al. Poem versus laparoscopic Heller myotomy in the treatment of esophageal achalasia: a case-control study from two high volume centers using the propensity score. J Gastrointest Surg 2020;24(3):505-515 